\title{
OBSERVAÇŐES SOBRE OS MOSQUITOS CULEX DA CIDADE DE SÃO PAULO, BRASIL *
}

\author{
Oswaldo Paulo FORATTINI ** \\ George Kenge ISHIATA*** \\ Ernesto Xavier RABELLO ** \\ Maria das Dores COTRIM **
}

RSPU-B/184

Foratrini, O. P. et al. - Observaçōes sobre os mosquitos Culex da cidade de São Paulo, Brasil. Rev. Saúde públ., S. Paulo, 7:315-30, 1973.

$\mathrm{R}_{\mathrm{ESUMO}}$ São apresentados os resultados obtidos na coleta de mosquitos do gênero Culex na área urbana da cidade de São Paulo, Brasil. Foram empregadas armadilhas luminosas automáticas tipo "New Jersey 50". Os resultados revelaram a presença de outras populações representadas principalmente por Culex chidesteri, C. dolosus e C. bidens as quais, em conjunto, chegaram algumas vezes a sobrepujar a de Culex pipiens fatigans. o maior rendimento foi obtido em áreas com abastecimento de água mas sem rede de esgotos. As coletas intradomiciliares revelaram franca predominancia de C. pipiens fatigans.

Unitermos: Culex *; Culex pipiens fatigans *; Mosquitos (área urbana) *.

Os dipteros Culicidae da área urbana da cidade de São Paulo, Brasil, tem merecido escassa atenção por parte dos investigadores. Alguns dados sobre essa fauna encontram-se esparsos em artigos que datam de certo tempo. Várias espécies têm sido assinaladas mas, no que concerne particularmente ao gênero Culex, a tendência geral tem sido a de rotular os exemplares como Culex pipiens fatigans, com raras exceções, como o encontro de Culex chidesteri, a partir de material coletado com a finalidade de estudos puramente taxonômicos (Correia \& Ramalho ${ }^{1}$, 1959). Essa regra é válida para observações realizadas em outras cidades do Brasil. Mormente ao se levar em consideração que o material de estudo foi constituido principalmente por exemplares do sexo

* Trabalho do Departamento de Epldemiologia e da Superintendêncla do Saneamento Ambiental (SUSAM), Diretoria de Combate a Vetores.

* Do Departamento de Epidemiologia da Faculdade de Saúde Pública da UsP - Av. Dr. Arnaldo, 715 - São Paulo, SP - Brasil.

** Da Diretoria de Combate a Vetores da Superintendência do Saneamento Amblental (SUSAM) do Estado de São Paulo - Rua Tamandaré, 649 - São Paulo, SP - Brasil. 
FORATTINI, O. P. et al. - Observações sobre os mosquitos Culex da cidade de são Paulo, Brasil. Rev. Saúde puibl., S. Paulo, 7:315-30, 1973.

feminino, cuja identificação nem sempre é fácil, dentro desse grupo.

O problema do mosquito representado pela população domiciliada de Culex pipiens fatigans na área metropolitana de São Paulo, por muito tempo foi relegado a plano secundário, no que pese a realização de algum estudo preliminar (MARCONDES et al. 4, 1951). A partir de 1970, tiveram início as atividades sistemáticas de controle desse inseto que estiveram, de início, a cargo do antigo SEMPDC (Serviço de Erradicação da Malária e Profilaxia da Doença de Chagas) e posteriormente, da SUSAM (Superintendência do Saneamento Ambiental). $O$ planejamento dos trabalhos previu a realização de avaliações mediante a captura contínua de formas adultas, com - emprego de armadilhas luminosas automáticas (Ishiata \& MAter 3 , 1970). Surgiu assim o problema da identificação dos mosquitos coletados, especialmente os do gênero Culex. Ao lado disso, a possibilidade de verificar a composição específica na amostra populacional obtida com essa técnica. A apresentação dos dados obtidos constitue a finalidade desta publicação.

\section{MATERIAL E MÉTODOS}

As armadilhas foram todas do modelo "New Jersey-50" (Estação Agrícola Experimental de Nova Jersey) (Figura 1), que funcionam, de maneira automática, com isca luminosa (Forattini 2, 1962). Selecionaram-se oito, cuja distribuição obedeceu a critérios de presença ou ausência de abastecimento de água e de rede de esgotos. Dessa maneira, as áreas escolhidas foram as seguintes:

A - Com abastecimento de água, rede de esgotos e galerias de água pluviais:

Armadilha $A 1$ - Localizada no Parque do Ibirapuera, na Av. Monte Libano, em terreno pertencente ao Departamento de Parques e Jardins da Prefeitura Municipal. A área apresenta a proximidade de criadouros representados por prédios em construção, ambientes domésticos e várias lagoas ornamentais com elevada poluição.

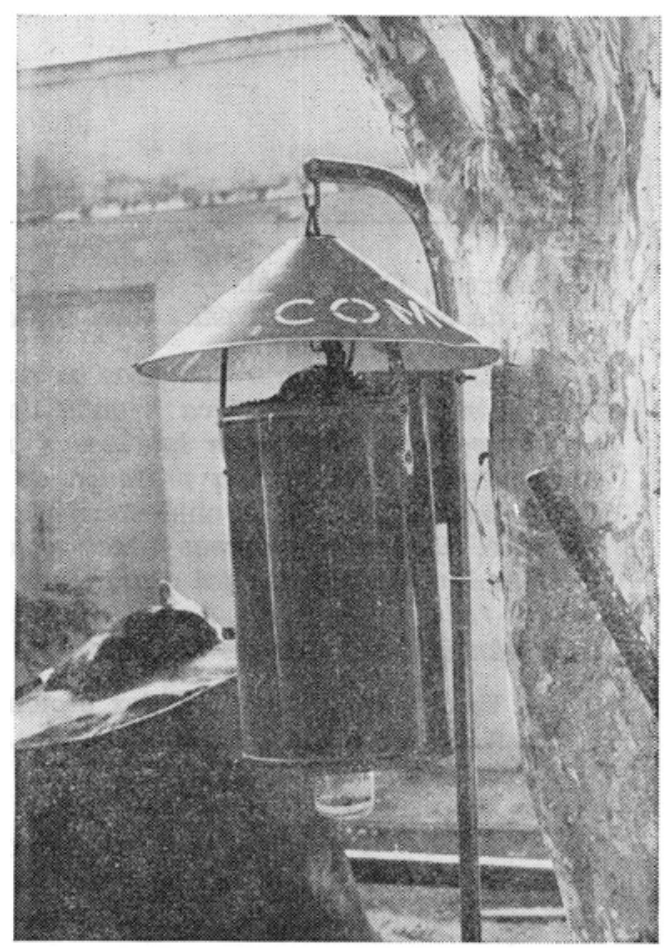

Fig. 1 - Armadilha luminosa automática modelo "New Jersey-50"

Armadilha $A 2$ - Situada à Rua Pires da Motta, dentro da propriedade pertencente à Faculdade de Medicina Veterinária da USP. Observa-se a existência de várias construções de prédios próximos, além de córrego com águas poluídas.

Armaditha $A 3$ - Instalada à Avenida Dr. Arnaldo na sede da Faculdade de Saúde Pública da USP. Notam-se a proximidade de várias obras em construção, bem como de grandes áreas destinadas a cemitérios. 
FORATTINI, O. P. et al. - Observaçóes sobre os mosquitos Culex da cidade de são Paulo, Brasil. Rev. Saúde públ., s. Paulo, 7:315-30, 1973.

Armadilha A4 - Situada no Bairro de Cidade Jardim, à Av. dos Amarillis. As características locais são de área intensamente arborizada, de cobertura vegetal alta e pouco alterada, com a existência de lagos ornamentais sem poluição. Dista cerca de $800 \mathrm{~m}$, em linha reta, do rio Pinheiros que é altamente poluído.

B - Com abastecimento de água mas sem rede de esgotos:

Armadilha $B 1$ - Instalada no Bairro de Vila Guilherme, na Sociedade Paulista de Trote. A área encontra-se rodeada de lagoas e alagadiços. Além da existência de descargas clandestinas de esgotos, ocorre o lançamento de lixo a céu aberto, por parte da Prefeitura Municipal.

Armaditha B2 - Localizada no Bairro de Vila Dalila, à Rua Inácio da Costa. As características locais permitem assinalar a presença do rio Aricanduva e de lagoas que se apresentam como coleções líquidas altamente poluídas.

Armaditha B3 - Situada no Bairro de Vila Mascote, à Rua São Paulo. Nas proximidades observa-se a presença do córrego Ribeirão do Cordeiro, onde são lançados os esgotos.

C - Sem abastecimento de água e sem rede de esgotos:

Armadilha C1 - Localizada no Bairro de Vila Inglesa, à rua n. ${ }^{\circ}$ 3. A área encontra-se rodeada por lagoas extensas que recebem lixo, bem como as valas de escoamento das águas servidas das casas.

O funcionamento dos aparelhos foi diário e regulado para ligar às 18:00h e desligar às 6:00 h do dia seguinte. As coletas compreenderam o tempo decorrido de abril de 1972 a março de 1973.
Com o objetivo de observar possíveis diferenças entre o material obtido através dessa técnica e a frequiência aos domicilios, executou-se série de coletas dentro das casas. Para tanto, foi escolhida uma habitação na proximidade de cada armadilha. Assim sendo, no período de dezembro de 1972 a março de 1973, foram realizadas duas capturas mensais em cada uma delas, durante a primeira metade da noite. Foi possível assim comparar os mosquitos encontrados dentro das casas com aqueles fornecidos, nessa mesma noite, pela armadilha correspondente.

A identificação do material coletado baseou-se preferentemente nos exemplares masculinos, pois o exame das genitálias permite determinação precisa. Quanto às fêmeas, as de algumas espécies como Culex bidens, C. chidesteri, C. dolosus e C. pipiens fatigans possibilitam determinação mais acertada do que outras. Acresce o fato de que, nem sempre os exemplares chegavam até o laboratório em perfeito estado. Nesses casos, ou o material era rotulado como Culex sp. ou então, desde que o caso o permitisse, levava-se em conta as proporções de machos existentes nos lotes.

\section{RESULTADOS}

O rendimento total das várias armadilhas em relação ao gênero Culex, durante 0 período supracitado pode ser apreciado pela análise das Tabelas 1,2 e 3. De maneira geral, pode-se observar a variação na incidência anual das médias horárias obedecendo os maiores valores às épocas quentes e chuvosas que correspondem ao periodo de novembro a março. Por outro lado, o major rendimento coube às áreas $B$ onde $o$ número de espécimens coletados chegou com frequiência, a valores consideráveis. Pouco se diferenciaram os resultados obtidos nas áreas $A$ e $C$. 
FORATTINI, O. P. et al. - Observaçбes sobre os mosquitos Culex da cidade de sáo Paulo, Brasil. Rev. Saúde públ., 8. Paulo, 7:315-30, 1973.

No que concerne à composição especi. fica, notou-se o comparecimento de, pelo menos, mais três representantes de Culex (Culex), além do Culex pipiens fatigans. Foram eles os Culex chidesteri, C. dolosus e C. bidens o primeiro dos quais, com frequiência, sobrepujando aquele mosquito, quanto ao número de exemplares capturados. Levando-se em conta os dados globais destas três espécies e comparados com os de C. pipiens fatigans, obtiveram-se as curvas dos grá. ficos (Figuras 2 a 9) correspondentes as diversas armadilhas. Pode-se observar apreciável paralelismo na incidência mensal dos dois grupos, em alguns casos, como na A4, havendo predominância constante ou temporal do conjunto chidesteri + dolosus + bidens.

Como foi mencionado, a tendência constante foi a queda até julho/agosto com elevaçóes subsequientes, mais precoces em algumas armadilhas do que em outras.

No que concerne às coletas domiciliares, os resultados obtidos constam da Tabela 4. Pode-se observar franca predominância do Culex pipiens fatigans dentro das casas, embora os outros tivessem aparecido de maneira apreciável nas armadilhas correspondentes.

Figuras 2 a 9 - Gráficos correspondentes às várlas armadilhas, mostrando a incidência das médias horárias (MH) de abril de 1972 (4/72) até março de 1973. A linha contínua corresponde ao Culex pipiens fatigans. A linha interrompida refere-se ao conjunto Culex chidesteri $+C$. dolosus $+C$. bidens.

\section{MH}

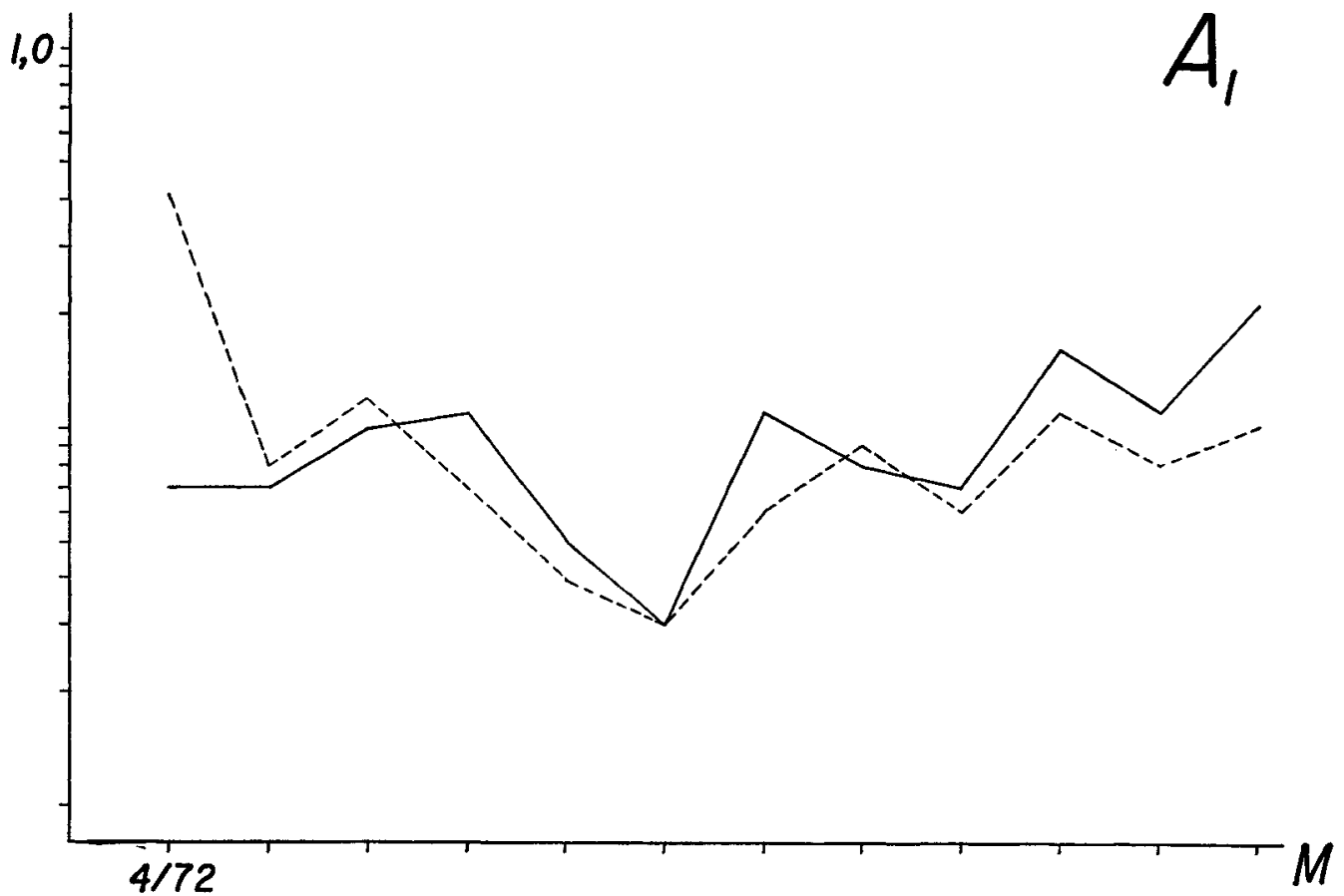

Fig. 2 
FORATTINI, O. P. et al. - Observaçóes sobre os mosquitos Culex da cidade de são Paulo, Brasil. Rev. Saúde públ., S. Paulo, 7:315-30, 1973.

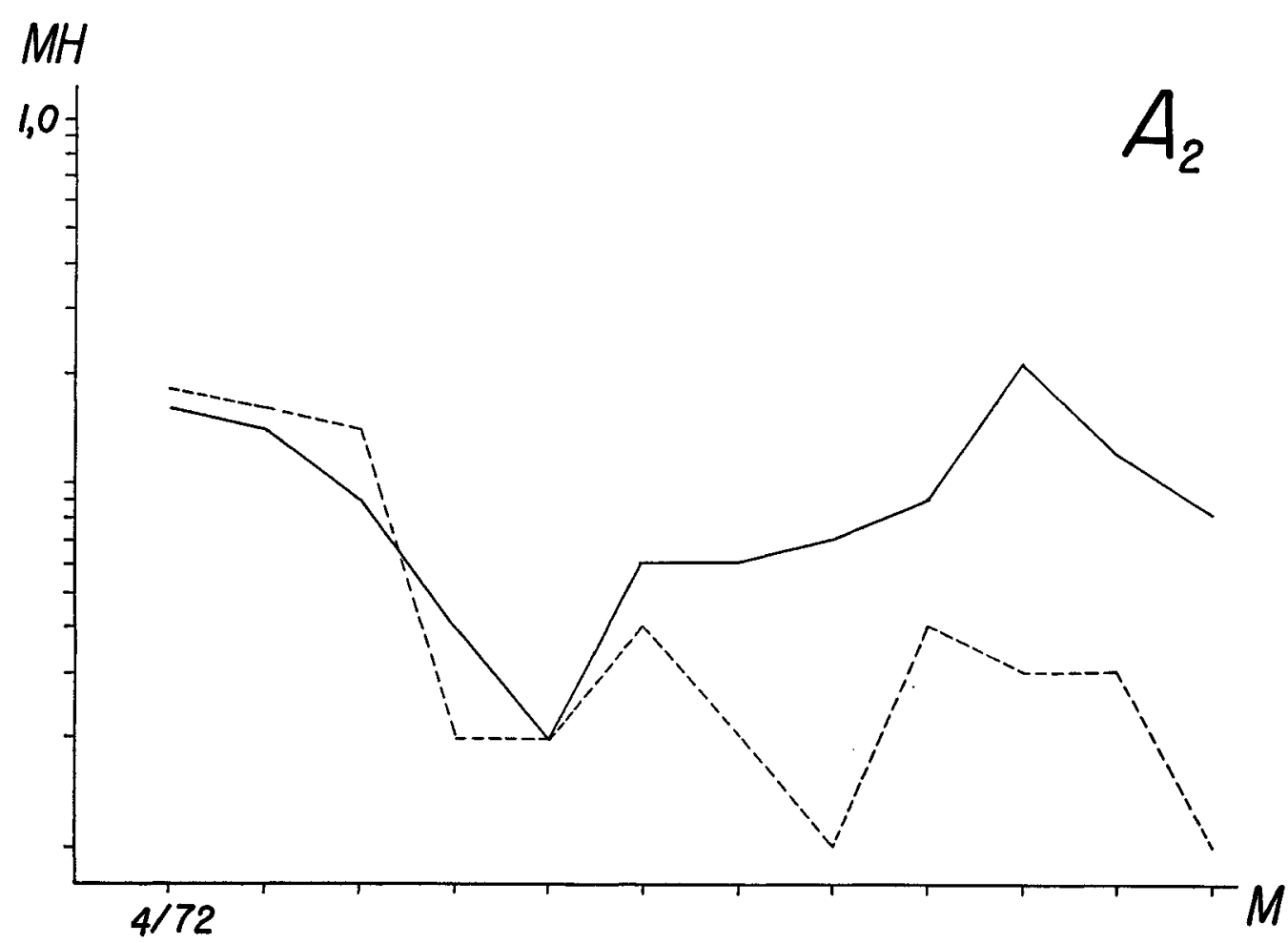

Fig. 3

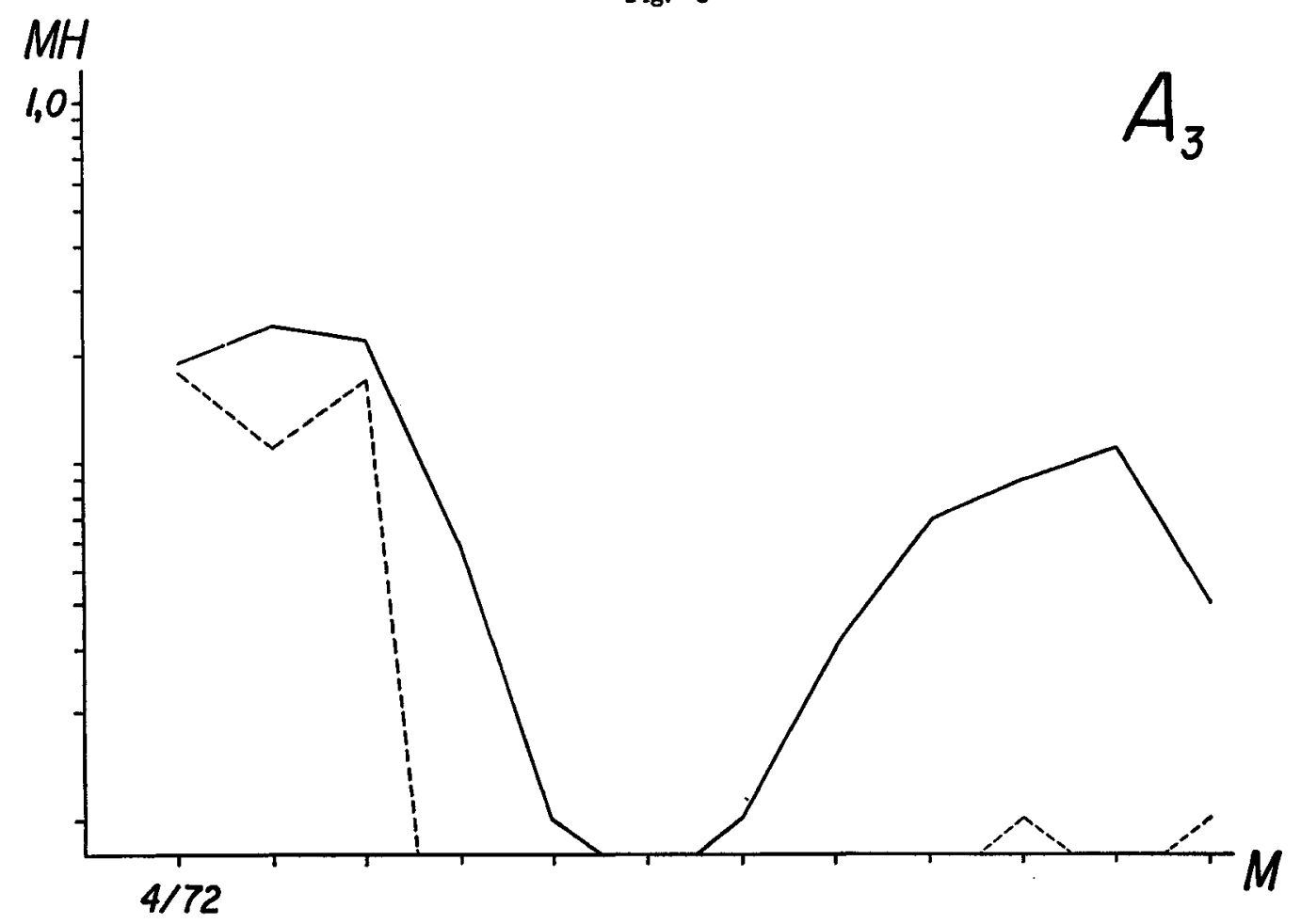

Fig. 4 
FORATTINI, O. P. et al. - Observaçōes sobre os mosquitos Culex da cidade de Săo Paulo, Brasil. Rev. Saúde pübl., S. Paulo, 7:315-30, 1973.

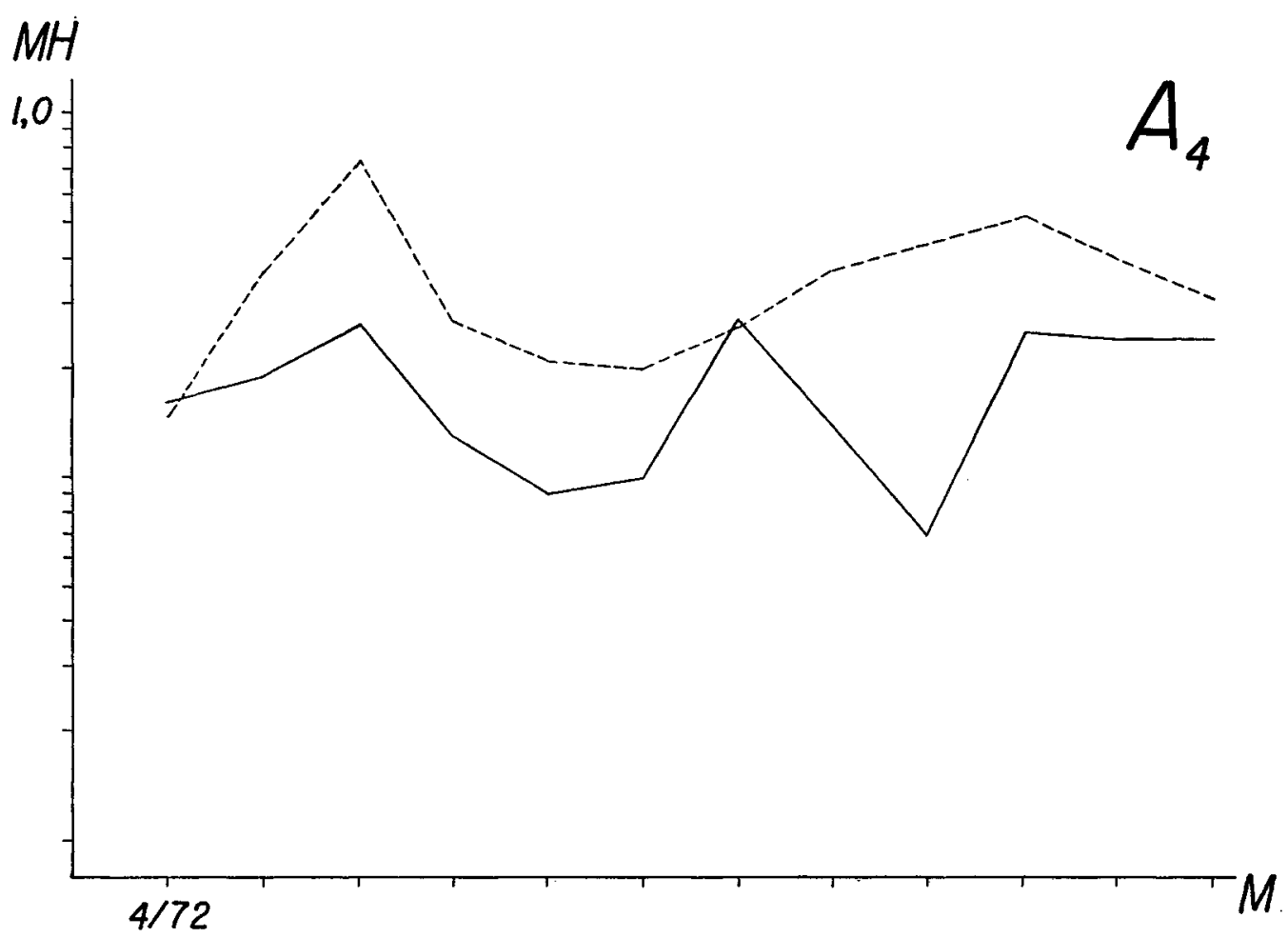

Fig. 5

$M H$

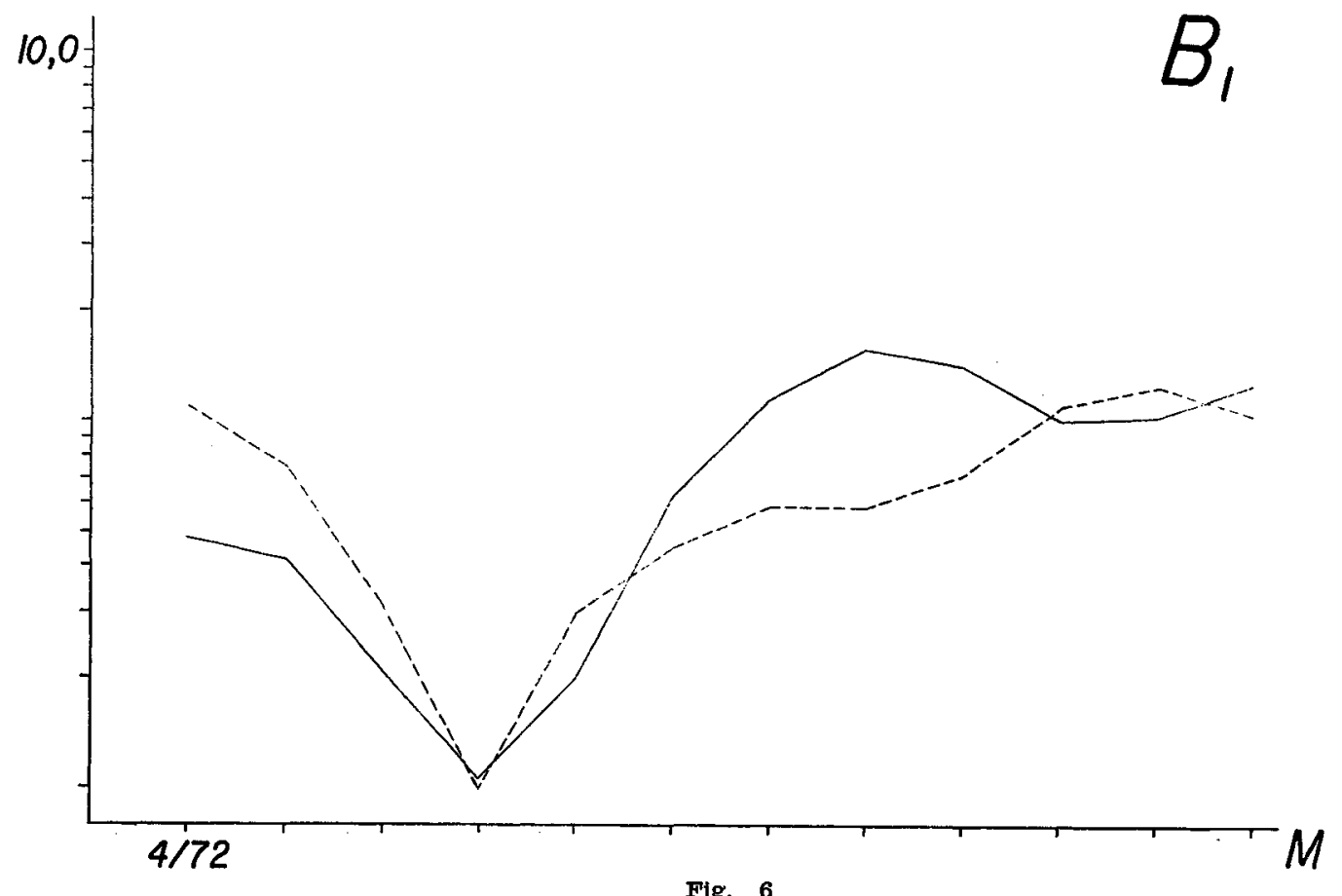

Fig. 6 
FORATTINI, O. P. et al. - Observaçóes sobre os mosquitos Culex da cidade de são Paulo, Brasil. Rev. Saude puibl., S. Paulo, 7:315-30, 1973.

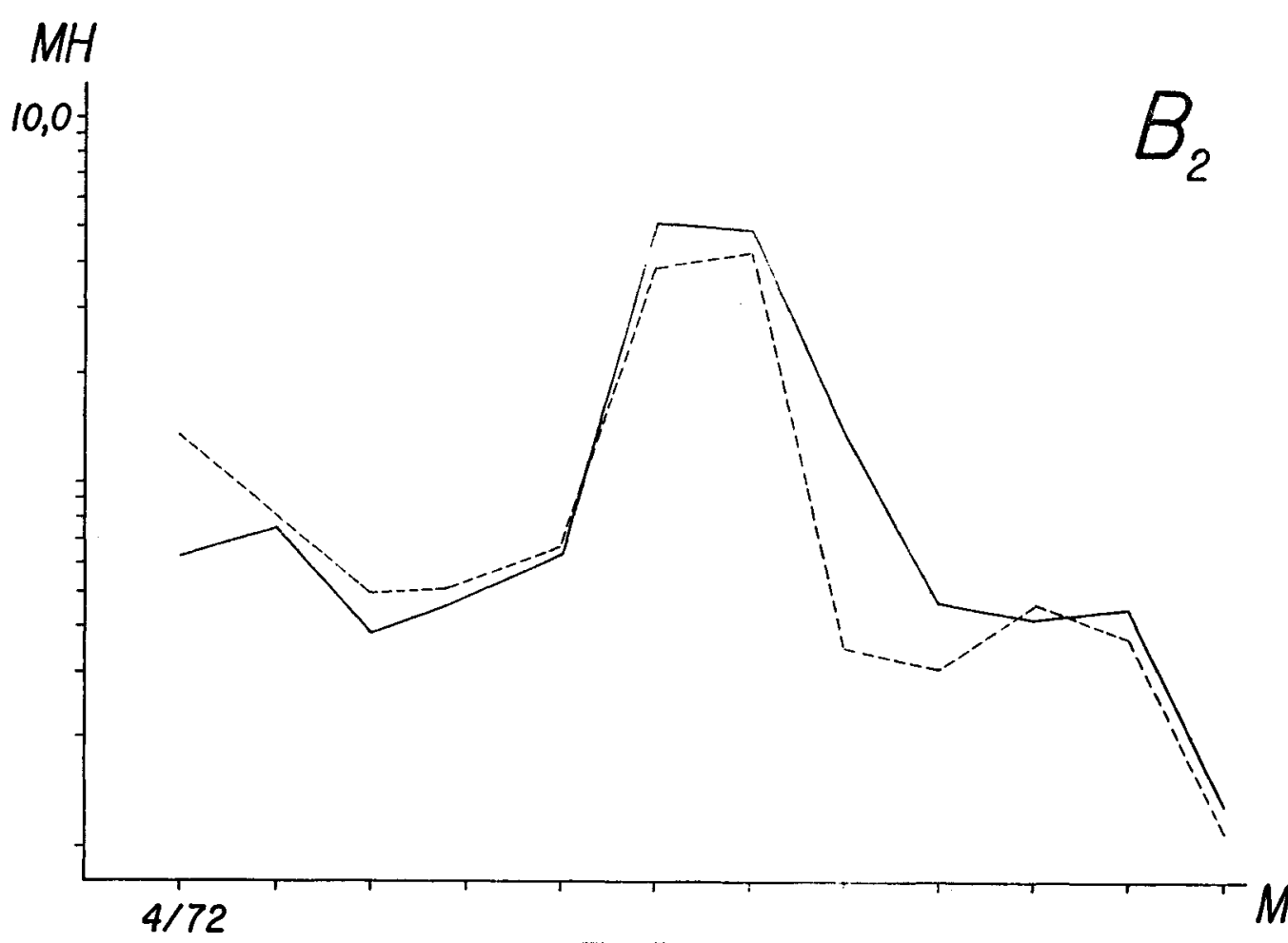

Fig. 7

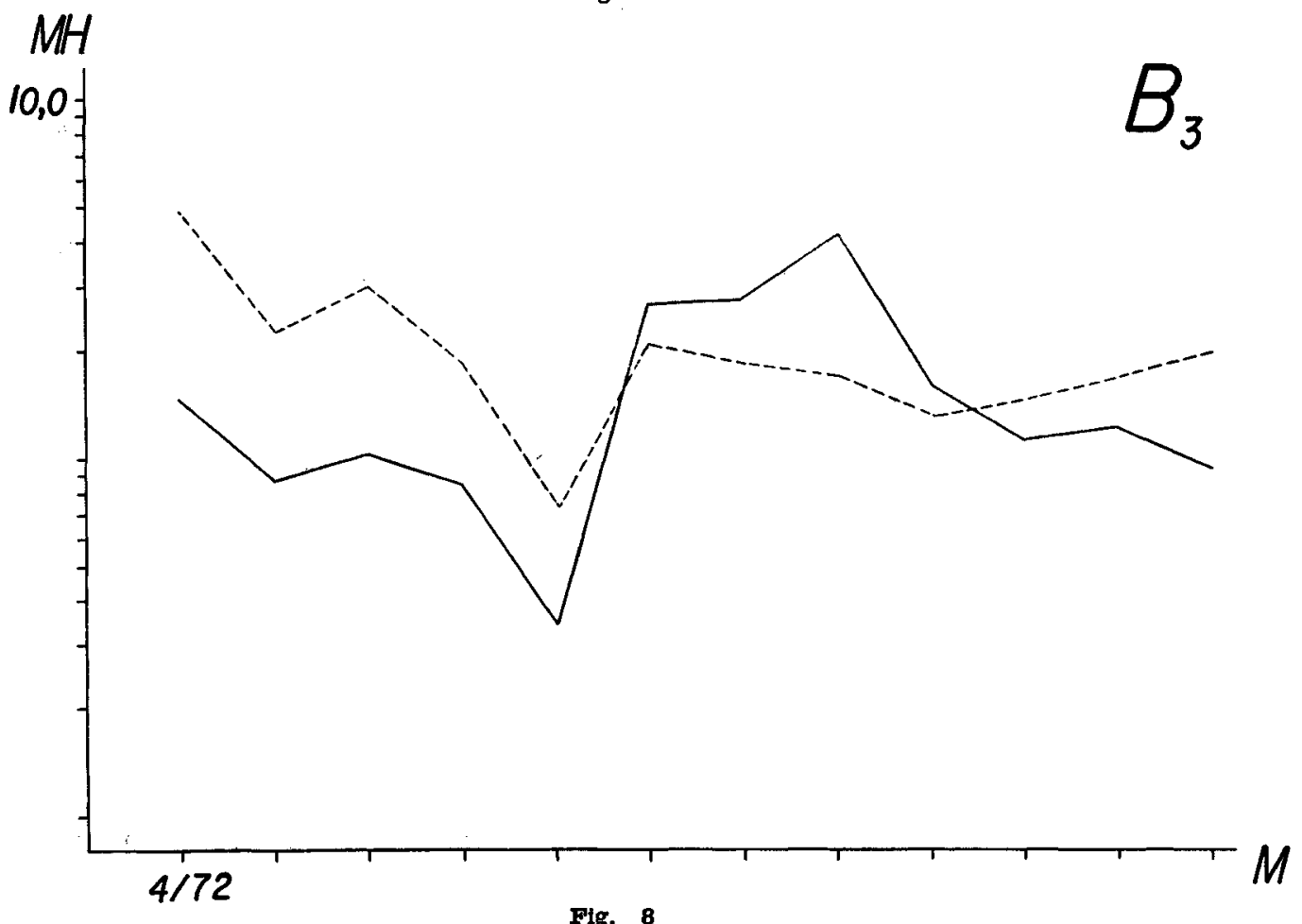

Fig. 8 
ForatTinI, O. P. et al. - Observaçós sobre os mosquitos Culex da cidade de sáo Paulo, Brasil. Rev. Saude puibl., S. Paulo, 7:315-30, 1973.

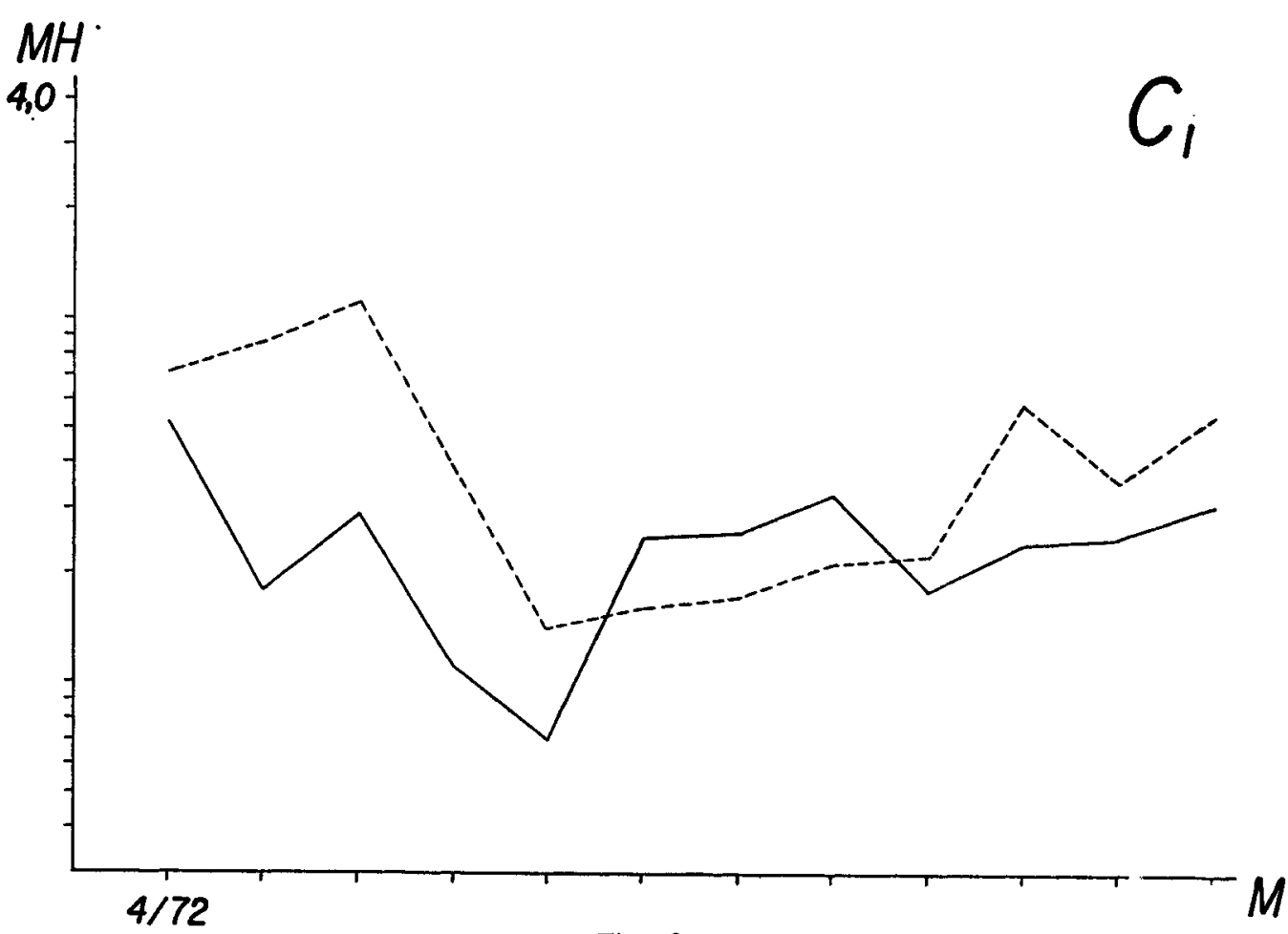

Fig. 9

COMENTARIOS

Os resultados dessas observaçóes vieram demonstrar a presença de outras populaçóes do gênero Culex que acompanhavam o Culex pipiens fatigans na área urbana da cidade de São Paulo. Nas regióes servidas de água e esgotos pode-se destacar dois grupos. O primeiro, representado pelas armadilhas A1 e A4, dispõe de vegetação abundante, artificial e natural, respectivamente. Nesses dois casos notou-se ampla incidência do grupo chidesteri + dolosus + bidens, chegando mesmo a sobrepujar o de fatigans. Isso deveu-se provavelmente, a maiores oportunidades de criadouros para aquelas espécies. Por outro lado, as correspondentes a $\mathbf{A 2}$ e A3, revelaram franca predominância de fatigans apresentando pois, nesse particular, aspecto contrário às duas anterio- res. Como se trata de áreas densamente habitadas e construídas, a poluição das águas é maior, no que pese a presença de rede de esgotos. Acresce o número considerável de obras em construçāo, favorecendo a ocorrência de coleçōes líquidas a céu aberto.

No caso de bairros servidos de água, mas sem esgotos, os resultados correspondentes às armadilhas B1, $\mathrm{B2}$ e B3 revelaram a maior produção. A predominância de fatigans foi geralmente observada embora o grupo chidesteri + dolosus + bidens, tenha sido bem representado, sobrepujando aquele em algumas ocasiōes. Compreende-se que o maior rendimento tenha sido nesta situação, uma vez que a existência de água encanada sem a correspondente rede coletora de esgotos enseja o despejo destes a céu aberto. Com isso, o grau 
FORatTINI, O. P. et al. - Observaçóes sobre os mosquitos Culex da cidade de såo Paulo, Brasil. Rev. Saúde puibl., s. Paulo, 7:315-30, 1973.

de poluição atinge valores altos. Acresce a presença de terrenos abandonados que recebem tais resíduos e se convertem assim em grandes focos desses mosquitos.

A área correspendente à armadilha $\mathrm{Cl}$ mostrou também boa produtividade para os dois grupos, embora sem a densidade das armadilhas B1, B2 e B3. A falta de água encanada faz com que provavelmente a poluição seja, em sua maior parte de origem doméstica. Ao contrário do que acontece com as da área $B$, onde o contingente industrial contribui sensivelmente. Daí pois, a menor densidade e a equivalência dos dois grupos de mosquitos, com frequiente predominância do chidesteri + dolosus + bidens.

Finalmente, as observações intradomiciliares revelaram franca predominância de fatigans em todas as áreas. $\mathrm{E}$ de supor, pois, que as coletas extradomiciliares nāo sejam suficientes para revelar a real densidade desse mosquito.

\section{CONCLUSOES}

Face ao exposto, é lícito deduzir o que segue:
1 - na área urbana de São Paulo, além do Culex pipiens fatigans ocorre a presença de outras populaçōes do mesmo gênero representadas, pelo menos, por Culex chidesteri, $C$. dolosus e C. bidens;

2 - essas populações, em conjunto, acompanham a incidência de fati. gans chegando frequientemente a ultrapassá-la;

3 - as áreas abastecidas de água enca. nada mas sem rede de coleta de esgotos, parecem ser as mais produtivas para as várias populações de Culex;

4 - a frequiência aos domicilios é predominantemente feita pelo Culex pipiens fatigans. $\mathrm{O}$ que permite concluir que o uso de armadilhas para controle da produção de mosquitos, somente terá valor quando for acompanhada de vigorosa determinação dos exemplares coletados.

Forattini, O. P. et al. - [Observations on Culex mosquitoes of S. Paulo City, Brazil]. Rev. Saúde públ., S. Paulo, 7:315-30, 1973.

Summary: With the use of New Jersey-50 light traps, a survey of Culex mosquitoes was made in the urban area of São Paulo City, Brazil. Beside Culex pipiens fatigans several other species were found, mainly represented by Culex chidesteri, $\mathrm{C}$. dolosus and $\mathrm{C}$. bidens. The combined incidence of these three populations follows nearly the fatigans one and frequently exceeding it. The most high levels of density were found at areas with water treatment but without sewage disposal. Domiciliary collections showed great Culex pipiens fatigans predominancy.

UNITERMS: Culex* Culex pipiens fatigans* Mosquitoes, urban area*. 
FORATTINI, O. P. et al. - Observaçóes sobre os mosquitos Culex da cidade de são Paulo, Brasil. Rev. Saúde públ., S. Paulo, 7:315-30, 1973.

\section{REFERENCIAS BIBLIOGRAFICAS}

1 - CORREA, R. R. \& RAMALHO, G. R. Culex (Culex) deanei, nova espécle do gênero Culex Linnaeus, 1758 (Diptera, Culicidae). Rev. Inst. Med. trop. S. Paulo, 1:141-8, 1954.

2 - FORATTINI, O. P. - Entomologia médica, Sáo Paulo. Fac. Higiene e Saúde Pública, 1962.

3 - IShIATA, G. K. \& MAIER, M. H. Combate ao Culex na cidade de Såo
Paulo, Brasil. [Apresentado ao Congresso Brasileiro de Higlene, 18.9, São Paulo, 1970].

4 - MARCONDES, M. N. et al. - Subsidio prestado pela secçáo de epldemiologia e profllaxla gerais a comissáo nomeada para estudar o problema do mosquito em São Paulo. Arg. Hig., $\mathbf{S}$. Paulo, 16:217-26, 1951.

Recebido para publicação em 4-9-1973

Aprovado para publicação em 9-10-1973 


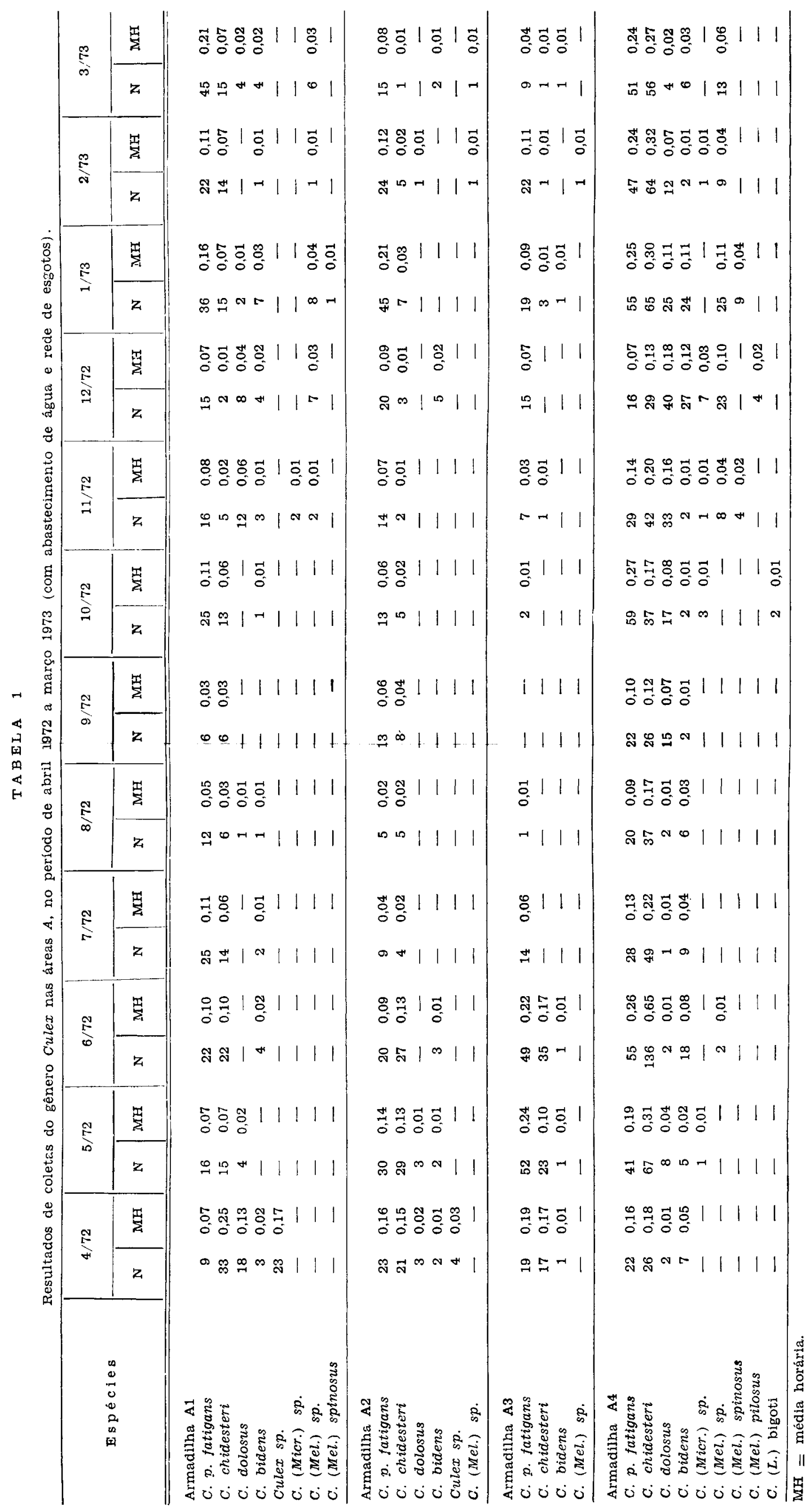




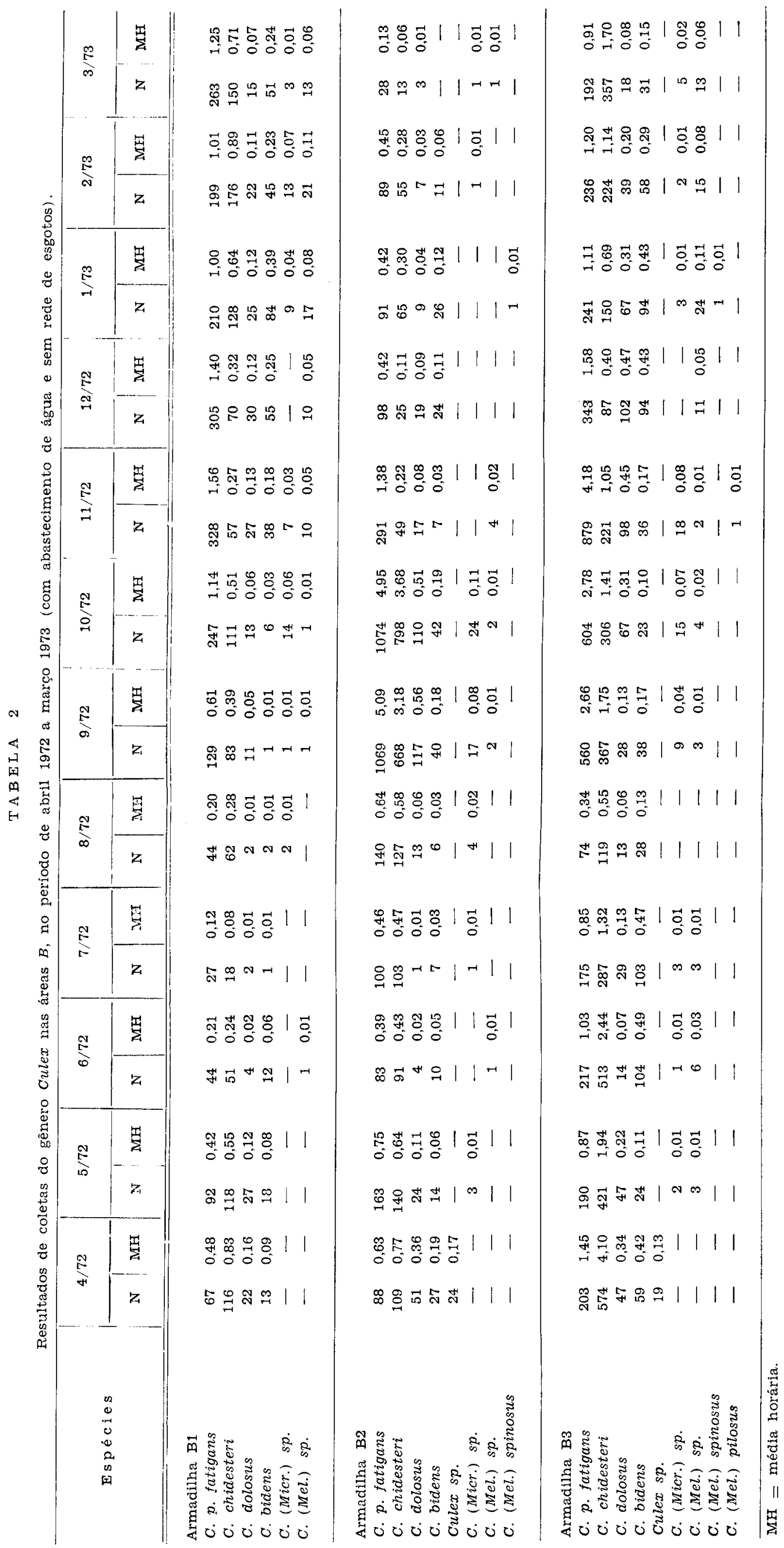




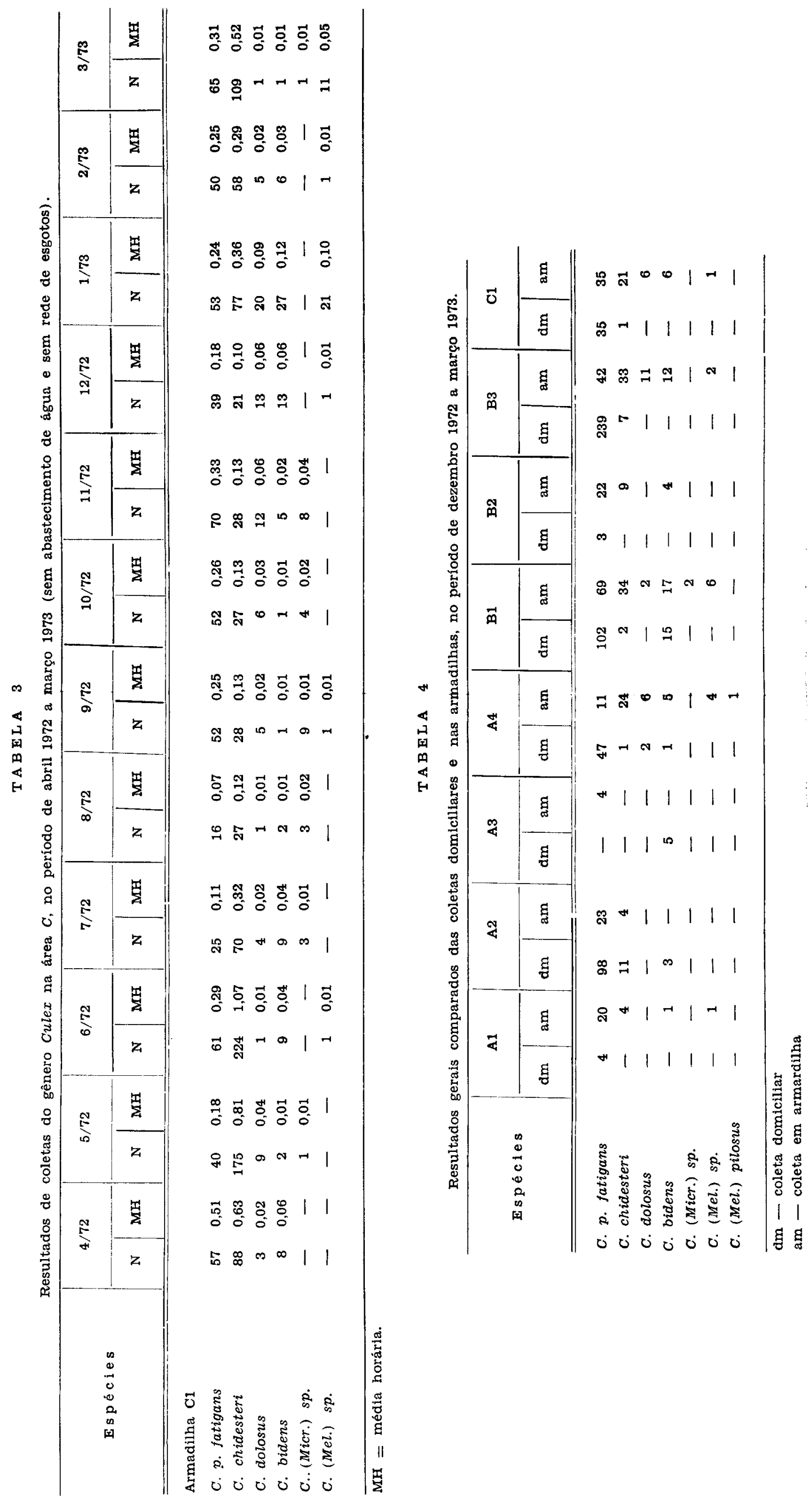

